\title{
An induction day for trainees in psychiatry
}

\author{
P. McLaren, P. MacDermott and S. Wood
}

\begin{abstract}
The importance of thorough induction courses for junior doctors when they start new jobs has been highlighted. This paper describes an induction course for trainees in psychlatry starting work in a community trust which included information on how to interact with the personnel department, on the services provided by the trust and on the organisation of education within the trust. The results of feedback from the trainees are presented showing that they found it a valuable experience.
\end{abstract}

The Standing Committee on Postgraduate Medical and Dental Education published a report (SCOPME, 1993) outlining the principles on which induction courses for junior doctors should be based. It stressed that induction is a process and not something that should be regarded as complete in one session or day and offers a variety of models and approaches. Induction in psychiatry presents special challenges as trainees in medical school may have little practical experience of working in a psychiatric service and it may have been one to two years since they completed their undergraduate psychiatry. Psychiatric trainees also have to work in community environments whereas most of their other jobs may have been based in the general hospital. Trainees also have to acquire new basic clinical skills such as communicating with patients and relatives, using the Mental Health Act, administering ECT and emergency tranquilisation. This paper presents a pilot format for an induction day for trainees in psychiatry joining a community trust.

\section{The induction day}

A basic principle in designing the induction day was that it should serve the trainees, the clinical tutor and the personnel department. The three basic elements for the trainees were learning about their terms and conditions of employment and how to interact with the personnel department; the educational context of their jobs and how to get the most out of their employment. The personnel function was considered particularly important, as juniors are often left to find out for themselves how to get on the pay roll, how to apply for annual and study leave, what their on-call commitment is, what they are expected to do on call and who to contact if they get into difficulties. The format was short presentations supplemented by written material, individual interviews and site visits.

\section{Preparation}

An essential prerequisite was that the induction day took place in protected time. Emergency clinical duties were covered by consultants and other career grade staff. The individuals with whom the trainees were to work were advised in advance not to arrange any clinical commitments for their trainees on the first day of their employment. Trainees were advised in advance that they were expected to attend. The day was arranged to take place in the management headquarters to ensure that the juniors were not called upon to do clinical duties, to introduce them to the layout of the building which housed the personnel department and also to facilitate the attendance of senior managers. The programme was as follows.

\section{Introduction to the trust by the medical director}

This described the overall management of the trust, the directorates, the sectors and some of the characteristics of the sectors, such as psychiatric morbidity. Topics also included the on-call arrangements and what the trainees were and were not expected to do on call.

Dealing with personnel by the personnel director and personnel officer

This presentation was supplemented in detail by the staff handbook appended for medical staff and included information on how to claim travel expenses and removal expenses, how to arrange leave and who to contact with problems. Examples of completed leave and travel forms were presented and included in the written material. 


\section{Postgraduate centre and library}

After a coffee break trainees received a presentation on the postgraduate centre and library facilities and on the education content of their posts from the clinical tutor.

Trainees were then given an opportunity to complete their starting forms to ensure they were put on the payroll. In the final phase of the morning the trainees were taken to visit the on-call facilities and shown how to use the mobile telephone which they were expected to carry on call. They were then taken to the ECT suite and given a demonstration of how to administer ECT. The trainees had lunch together without senior staff being present and the afternoon was split between site visits when they were shown around by senior nursing staff and individual interviews with clinical tutor on educational aims and objectives for their jobs.

\section{Findings}

Five trainees attended: three registrars and two senior house officers. All trainees completed and returned anonymised feedback forms. They were asked to rate each section of the programme by scoring it for helpfulness on a scale from 1 (not at all) to 5 (very). All sections of the programme were considered helpful (mean score 3.8 to 5.0).

In addition, trainees were asked an open question on how they thought the day could be improved. Two trainees suggested a section on the Mental Health Act and one suggested a talk from pharmacist on basic prescribing in psychiatry. The same trainee suggested getting one of the trainees who had already working in the trust to give a presentation. Another suggested extending the site visits to all those sites visits to all those sites they would cover on call and not just where they would be based.

In terms of resources the day required a full day for the clinical tutor, a half day for the medical director and lecture time form the personnel director, personnel officer postgraduate Secretary and nursing staff. Other costs included written materials, the most significant being the staff handbook, and coffee.

The induction day was regarded as a positive and helpful experience for those who participated. Acting on the feedback, the sections on educational contracts and the postgraduate centre may be confined to written information and presentations on the Mental Health Act and drug prescribing will be included. While the resource implications of this model are not insignificant, the benefits in terms of efficient working, morale of the trainees and the efficient running of the organisation were considerable and justify its further development.

\section{Acknowledgements}

Thanks to Christine Hull and Clare Gibson for their help in preparing this induction day.

\section{References}

SCOPME (1993) A Good Start: a report on job induction for hospital doctors and dentists in training. The Standing Committee on Postgraduate Medical and Dental Education.

*P. McLaren, Clinical Tutor, Canterbury and Thanet Community Healthcare, Westbrook Centre, 150, Canterbury Road, Margate, Kent CT9 5DD; P. MacDermott, Director of Human Resources, Canterbury and Thanet Community Healthcare, Trust HO; and S. Wood, Medical Director, Canterbury and Thanet Community Healthcare, Trust HO, St Martin's Hospital, Littlebourne Road, Canterbury CT1 ITD

*Correspondence 